\title{
Case report and literature review: Horner syndrome subsequent to endoscopic thyroid surgery
}

Yu Min ${ }^{1 \dagger}$, Hang Chen ${ }^{1+}$, Xing Wang ${ }^{1}$, Ying Huang ${ }^{2}$ and Guobing Yin ${ }^{1 *}(\mathbb{D}$

\begin{abstract}
Background: Horner syndrome (HS), mainly characterized by symptoms including ptosis, miosis, and anhidrosis on the affected face, is a condition that is well documented but rarely reported as a postoperative complication of thyroidectomy, particularly in endoscopic thyroid surgery (ETS). We hereby report a case of HS due to ETS with a brief literature review on this topic.

Case presentation: A 31-year-old female was admitted to our hospital with an unexpected physical examination finding of two thyroid nodules that were hypoechoic, had an irregular shape, and exhibited calcification. Subsequently, the results of a fine-needle aspiration (FNA) biopsy from the thyroid nodules and BRAF ${ }^{\mathrm{V} 600 \mathrm{E}}$ mutation further confirmed the malignancy of these nodules. Thus, total thyroidectomy combined with central lymph node dissection (CLND) by ETS via the bilateral axillo-breast approach was performed on this patient. Histology confirmed the diagnosis of papillary thyroid microcarcinoma (PTMC) concurrent with Hashimoto's thyroiditis (HT). However, this patient developed HS with ptosis in her left eye on postoperative day 3. All symptoms gradually resolved before the 3-month follow-up.
\end{abstract}

Conclusion: HS subsequent to ETS is a rare complication. Thus, standardized and appropriate operative procedures, as well as subtle manipulation, are essential in preventing and reducing the occurrence of HS. In addition, the early diagnosis and management of this rare complication are also important for a favorable outcome.

Keywords: Horner syndrome, Endoscopic thyroid surgery, Thyroid, Thyroid cancer, Complication

\section{Background}

Horner syndrome (HS) was first formally described by Horner in 1869 [1], and the classic symptoms include partial ptosis (drooping of the upper eyelid), miosis (constricted pupil), and ipsilateral facial anhidrosis (loss of the ability to sweat normally from one side of the face). HS [2] mainly occurs due to impairment of

\footnotetext{
*Correspondence: yinguobing@cqmu.edu.cn

${ }^{\dagger}$ Yu Min and Hang Chen contributed equally to this work

${ }^{1}$ Department of Breast and Thyroid Surgery, The Second Affiliated

Hospital of Chongqing Medical University, No.74, Linjiang Rd, Yuzhong

Dist, Chongqing 404100, People's Republic of China

Full list of author information is available at the end of the article
}

the oculosympathetic pathway. Clinically, HS is usually observed in patients with large neck masses or those undergoing head and neck surgery. For instance, Kaelin et al. [3] reported the first case of HS subsequent to thyroidectomy in 1915. Since then, approximately 25 cases of HS associated with thyroidectomy have been reported in the published literature. In general, the incidence of thyroidectomy-related HS is low, as it is approximately $0.2 \%$ [4]. With outstanding postoperative neck cosmetic results, minimally invasive thyroid surgery, such as endoscopic thyroid surgery (ETS) and robotic-assisted endoscopic thyroidectomy (RAET), has been widely introduced to clinical practice in recent years [5]. However, postoperative complications, such as HS, were also

(c) The Author(s) 2021. This article is licensed under a Creative Commons Attribution 4.0 International License, which permits use, sharing, adaptation, distribution and reproduction in any medium or format, as long as you give appropriate credit to the original author(s) and the source, provide a link to the Creative Commons licence, and indicate if changes were made. The images or other third party material in this article are included in the article's Creative Commons licence, unless indicated otherwise in a credit line to the material. If material is not included in the article's Creative Commons licence and your intended use is not permitted by statutory regulation or exceeds the permitted use, you will need to obtain permission directly from the copyright holder. To view a copy of this licence, visit http://creativecommons.org/licenses/by/4.0/. The Creative Commons Public Domain Dedication waiver (http://creativecommons.org/publicdomain/zero/1.0/) applies to the data made available in this article, unless otherwise stated in a credit line to the data. 
observed with these novel surgical approaches [6, 7]. Therefore, standard surgical procedures and detailed postoperative follow-ups are needed to effectively avoid such surgical technique-related complications.

In the present study, we report a female patient who developed HS secondary to ETS. In addition, we also discuss the possible causes of this rare complication, its management and the follow-up results based on a comprehensive literature review and our own experiences.

\section{Case presentation}

A 31-year-old Chinese female was admitted to the Department of Breast and Thyroid Surgery with the unexpected discovery of two thyroid nodules $(0.51 \times 0.47 \times 0.47 \mathrm{~cm}$ and $0.50 \times 0.54 \times 0.28 \mathrm{~cm}$, respectively) during a routine physical examination 7 days prior (Fig. 1). The Thyroid Imaging Reporting and Data System (TI-RADS) scores of the nodules were classified as $4 \mathrm{~b}$ and $4 \mathrm{~b}$, respectively. The patient was in a good general condition and did not have a history of chronic illness or smoking or drinking habits. Additionally, she did not complain about neck swelling or other discomforts when her medical history was collected. Only the serum levels of the thyroid peroxidase antibody (TPOAb, $127.6 \mathrm{IU} /$ $\mathrm{ml}$, reference $0.0-34 \mathrm{IU} / \mathrm{ml}$ ) and thyroid globulin antibody (TgAb, $438.9 \mathrm{IU} / \mathrm{ml}$, reference $0.0-115 \mathrm{IU} / \mathrm{ml}$ ) were elevated according to the laboratory test results. After admission, a fine-needle aspiration (FNA) biopsy and $\mathrm{BRAF}^{\mathrm{V} 600 \mathrm{E}}$ gene test were performed. The results (atypical cells and $\mathrm{BRAF}^{\mathrm{V} 600 \mathrm{E}}$ mutation) revealed that these nodules were strongly suspected to be malignant.

Therefore, with for a goal of a satisfactory postoperative neck appearance, the patient underwent endoscopic thyroidectomy via the bilateral axillo-breast approach (BABA) on the 3rd day of hospitalization. Initially, the operational vision and manipulation spaces were established through two subcutaneous tunnels in the chest wall. Then, with the aid of endoscopy, a coagulation hook was used to separate the neck white line and anterior cervical muscles and further expose the whole thyroid gland. The two nodules were located in the superior part and the isthmus of the right thyroid gland, and they had hard and fixed surfaces and unclear boundaries. Thus, the right lobe and isthmus of the thyroid gland were simultaneously removed by an ultrasound knife, and then, all the samples were sent for intraoperative frozen section biopsies (FSBs). The results of the FSBs suggested papillary thyroid microcarcinoma (PTMC, Fig. 2) and Hashimoto's thyroiditis (HT, Fig. 3). For this reason, the central lymph node (CLN) and residual thyroid tissue were resected. The postoperative pathological examination findings were consistent with the FSBs results and did not show lymph node metastasis $(0 / 2)$.
However, on the 3rd postoperative day, the patient complained of upper eyelid drooping on the left side (Fig. 4). Thus, a comprehensive ocular examination was performed by a neurologist and ophthalmologist together. The left upper eyelid ptosis covered the corneal limbus for nearly $4 \mathrm{~mm}$ with an unequal pupil diameter (right: $4 \mathrm{~mm}$, left: $2 \mathrm{~mm}$ ). In addition, ipsilateral anhidrosis was also confirmed on the face. These symptoms led to the final diagnosis of HS. Hence, the patient received a detailed and reasonable explanation of this rare complication and was told that HS is a curable symptom. Then, she agreed to receive adjuvant neurotrophic therapy with mecobalamin $(0.5 \mathrm{mg}$, oral administration, three times a day) and vitamin B1 (0.1 g, intramuscular injection, once a day) for 7 days before being discharged. No other complications, such as dyspnea, inflammation, or vocal cord palsy, were observed in this patient during the 12-day hospitalization period.

During the first 3-month follow-up, all symptoms of HS were significantly resolved without recurrence, and the patient did not report other symptoms, such as vision loss, photophobia, or cognitive dysfunction. In addition, she appreciated the timely diagnosis and treatment of HS and was fully satisfied with the aesthetic result of ETS. The timeline is described in Table 1.

\section{Discussion \\ Epidemiology of HS}

HS is a rare disease and occurs at a frequency of approximately 2.93 per 100,000 people, as reported in a recent nationwide population-based cohort study [8]. In addition, the cumulative 10-year incidence of HS in the adult population was reported to be 2.95 per 100,000 adults. However, it is relatively lower in the pediatric population, with an incidence of 2.12 per 100,000 Korean children and 1.42 per 100,000 American children, respectively. Additionally, HS can occur at any age within any ethnic group $[8,9]$.

\section{Neuroanatomy and etiology of HS}

Understanding the sympathetic innervation of the eye is pivotal to revealing the possible etiology of HS [10]. The oculosympathetic pathway contains three types of neurons. The first-order neurons are in the hypothalamus, with axons traveling through the brainstem and spinal cord that synapse in the lower cervical or upper thoracic spinal cord. Consequently, lesions stemming from the brainstem and cervical cord can present as first-order neuron HS. Then, second-order neurons originate from this spinal nucleus, travel through the upper chest cavity, and synapse in the superior cervical ganglion. For this reason, lesions in the upper chest cavity, such as pancreatic tumors, or iatrogenic interventions including but 


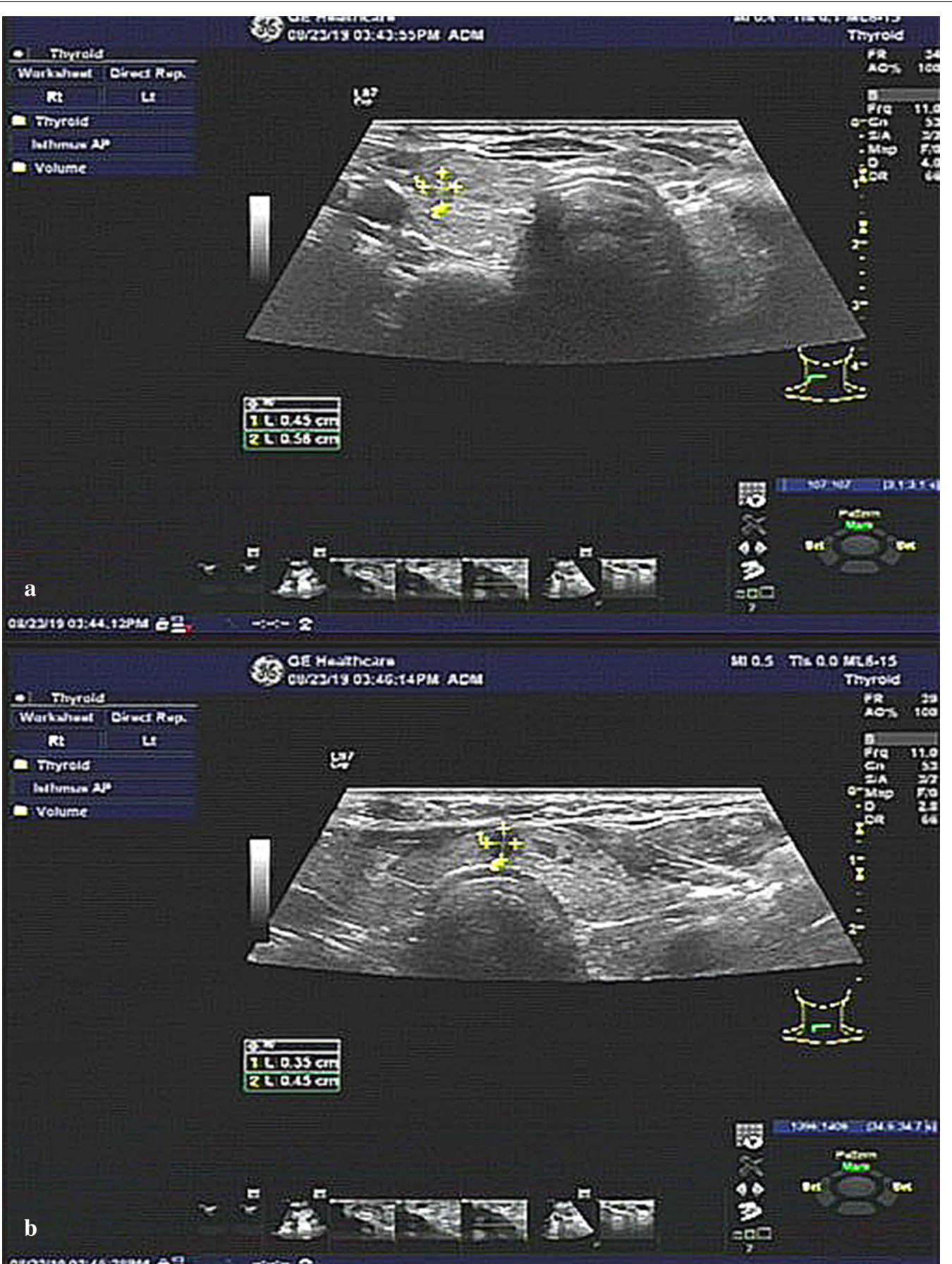

Fig. 1 a Ultrasound imaging demonstrated a nodule $(0.51 \times 0.47 \times 0.47 \mathrm{~cm})$ that was located at the middle and upper part of the right thyroid gland; $\mathbf{b}$ Ultrasound imaging demonstrated a nodule $(0.50 \times 0.54 \times 0.28 \mathrm{~cm})$ that was located at the isthmus of the thyroid

not limited to thyroidectomy and radical neck dissection can induce signs and symptoms of HS. In addition, thirdorder neurons originating in the superior cervical ganglion travel along the carotid artery system to reach the orbit and eye, which is close to the internal carotid artery.
Therefore, pathologies in the neck, skull base, and orbit, as well as carotid diseases, can cause third-order HS [2].

Although the so-called typical risk factors for HS are well known, only approximately half of HS cases can be explained by a specific cause $[8,11]$. Nonetheless, 


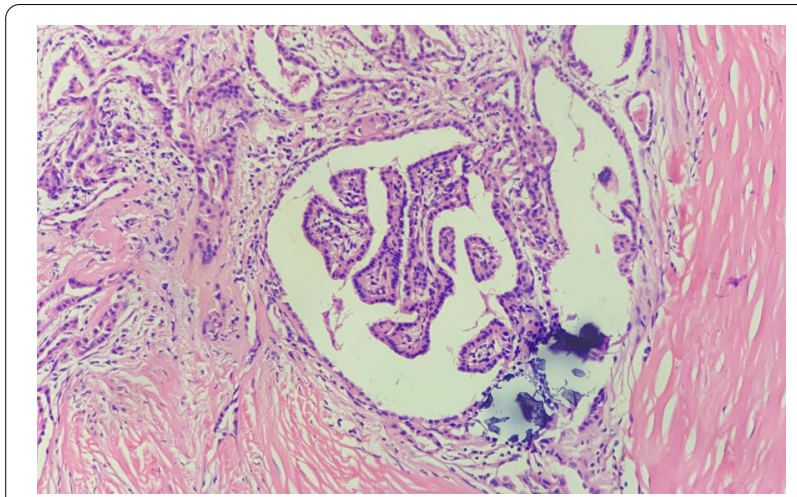

Fig. 2 Microscopic image of PTMC from this patient, HE staining, $\times 20$ magnification

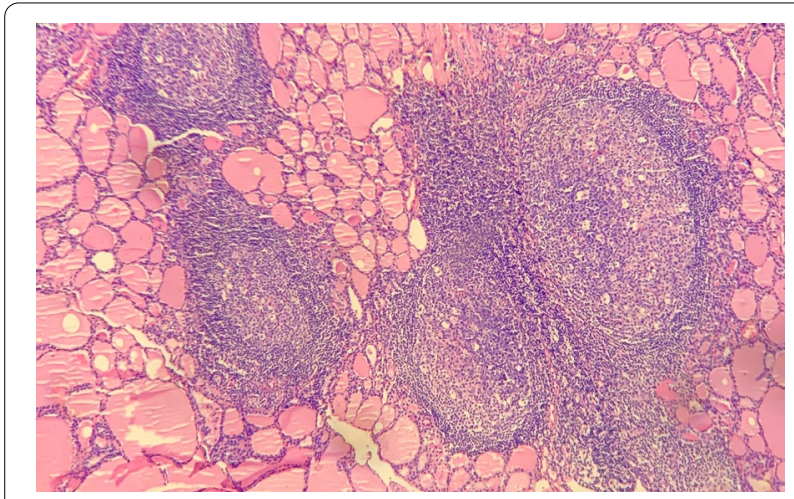

Fig. 3 Microscopic image of HT (Hashimoto's thyroiditis) from this patient, HE staining, $\times 10$ magnification

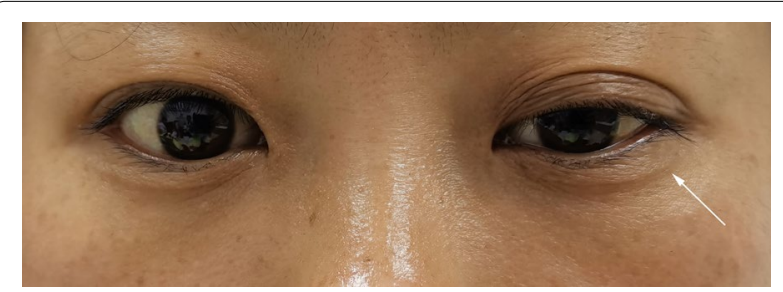

Fig. 4 A 31-year-old female patients who underwent ETS, and suffered from ptosis (white arrow) on the 3rd day after the operation

excluding HS cases with idiopathic and undetermined etiologies, the surgery procedure was the most frequent cause of adult HS, with a rate of $58 \%$ in the study by Han et al. and $24.7 \%$ in the study by Sabbagh et al. [8, 11]. This result was also observed clearly in the pediatric population [12]. Among these patients, cervical surgery plays the predominant role in the occurrence and development of HS [10], followed by direct invasion of the
Table 1 The timeline of the diagnosis and treatment process

\begin{tabular}{|c|c|}
\hline Timeline & Diagnosis and treatment process \\
\hline Dec 18th, 2019 & Unexpected found two thyroid nodules \\
\hline Dec 24th, 2019 & $\begin{array}{l}\text { Hospitalized in the department of Breast and Thyroid } \\
\text { Surgery }\end{array}$ \\
\hline Dec 25th, 2019 & Fine-needle aspiration was performed \\
\hline Dec 26th, 2019 & Comprehensive department internal discussion \\
\hline Dec 27th, 2019 & Endoscopic thyroid surgery was performed \\
\hline Dec 30th, 2019 & $\begin{array}{l}\text { The ptosis and anhidrosis were showed up on the } \\
\text { left eye }\end{array}$ \\
\hline Dec 31st, 2019 & HS was diagnosed \\
\hline Dec 31st, 2019 & Neurotrophic support was immediately administered \\
\hline Jan 05th, 2020 & Discharged from the hospital \\
\hline Mar 27th, 2020 & The symptoms of HS were gradually resolved \\
\hline
\end{tabular}

tumor, trauma, stroke, central venous catheter insertion, and carotid artery diseases. Notably, in one review article, thyroid pathologies were the most frequent causes of neck mass-related HS, accounting for approximately $1.3 \%$ of neck mass-related HS cases. [13]. Interestingly, however, when the main outcome measures were postoperative complications of neck surgery, especially thyroidectomy, the incidence of HS was significantly low. For instance, as two retrospective studies determined, HS only accounted for $0.2-0.3 \%$ of postoperative complications in patients who underwent thyroid surgery $[4,14]$. With an increasing prevalence of thyroid malignancy around the world $[15,16]$, surgery remains an important initial choice for patients with thyroid carcinoma. Despite the significant development of minimally invasive surgical techniques for surgery, especially ETS with or without robotic assistance, some rare complications, such as HS, were still observed with these methods. To our knowledge, including the patient in our study, approximately twenty-five patients have developed HS due to thyroid surgery in recent years. In addition, only 4 cases among these patients were due to the ETS. The clinical characteristics of the cases are summarized in Table $2[4,6,7$, 14, 17-31]. Among these patients, the patients with HS most commonly underwent TT with lymph node dissection, especially with lateral lymph node dissection (LLND) [4, 6, 7, 14, 20, 23-26, 28-30]. In general, HS is not very difficult to diagnose in patients with a recent history of head or neck surgery and obvious symptoms during the postoperative hospital stay.

\section{Clinical manifestations}

As previously described, HS is a consequence of sympathetic disruption that can lead to a series of nerve dysfunction complications. The main symptoms of HS, 
Table 2 Reported cases of Horner syndrome related to thyroid surgery

\begin{tabular}{|c|c|c|c|c|c|c|}
\hline References & Case & Scopes of operation & Histopathology & Approach & Symptoms & Time to resolution \\
\hline Zhang [17] & 1 & Nodule & Benign nodule & MWA & Myosis, ptosis & Incomplete resolved \\
\hline Aslankurt [21] & 1 & ST & Nodular goiter & NM & $\begin{array}{l}\text { Ptosis, } \\
\text { anhidrosis }\end{array}$ & No improvement \\
\hline Perréard [22] & 1 & ST & Benign nodule & NM & Miosis, ptosis & 3 months \\
\hline Cozzaglio [23] & 1 & $\mathrm{TT}$ & Toxic nodular goiter & NM & Ptosis, miosis & 3 days \\
\hline Italiano [24] & 1 & $\mathrm{TT}$ & Nodular goiter & Conventional & $\begin{array}{l}\text { Myosis, ptosis, mild enoph- } \\
\text { thalmos }\end{array}$ & 2 months \\
\hline Tan [7] & 1 & TT & FTC & ETS & NM & 3 months \\
\hline Seneviratne [25] & 1 & $\mathrm{TT}$ & Nodular goiter & NM & Ptosis, enophthalmos & 12 months \\
\hline Sandoval [26] & 1 & $T T+C L N D$ & ATC & Conventional & Ptosis, mild enophthalmos & NM \\
\hline Meng [6] & 2 & $\mathrm{TT}+\mathrm{CLND}$ & $\begin{array}{l}\text { PTMC in } 1 \text { patient; PTC in } 1 \\
\text { patient }\end{array}$ & ETS & $\begin{array}{l}\text { a: miosis } \\
\text { b: miosis, } \\
\text { ptosis }\end{array}$ & 11 and 1 months \\
\hline Foma [27] & 1 & ET & $\begin{array}{l}\text { Parapharyngeal ectopic } \\
\text { goiter }\end{array}$ & Conventional & $\begin{array}{l}\text { Miosis, ptosis, enophthal- } \\
\text { mos }\end{array}$ & 12 months \\
\hline Sapalidis [28] & 1 & $T T+C L N D+L L N D$ & PTMC & NM & Miosis, ptosis & 3 days \\
\hline Mastronikolis [29] & 1 & $T T+B L L N D$ & MTC & Conventional & Miosis, ptosis & 4 weeks \\
\hline Lee [4] & 5 & $\begin{array}{l}2 \text { with } \\
T T+C L N D+L L N D \\
3 \text { with } \\
T T+B C L N D+B L L N D\end{array}$ & Thyroid malignancy & Conventional & NM & NM \\
\hline $\mathrm{Hu}[30]$ & 1 & Lobectomy + CLND + LLND & PTMC & ETS & $\begin{array}{l}\text { Miosis, ptosis, enophthal- } \\
\text { mos }\end{array}$ & 12 months \\
\hline Kang [14] & 1 & NM & NM & RAET & NM & NM \\
\hline Lee [31] & 1 & NM & NM & RAET & NM & NM \\
\hline McCrory [19] & 1 & Lobectomy & Neuroma & NM & Ptosis miosis anhidrosis & Incomplete resolved \\
\hline Punda [20] & 1 & $T T+B C L N D+B L L N D$ & PTC & Conventional & Ptosis miosis anhidrosis & Incomplete resolved \\
\hline Demiral [18] & 1 & TT & Nodular goiter & NM & Ptosis miosis & 6 months \\
\hline Present case & 1 & $\mathrm{TT}+\mathrm{CLND}$ & PTMC & ETS & Miosis, ptosis & 3 months \\
\hline
\end{tabular}

$T T$ total thyroidectomy, ST subtotal thyroidectomy, ET ectopic thyroidectomy, CLND central lymph node dissection, LLND lateral lymph node dissection, BCLND bilateral central lymph node dissection, BLLND bilateral lateral lymph node dissection, PTC papillary thyroid carcinoma, PTMC papillary thyroid microcarcinoma, FTC follicular thyroid carcinoma, ATC anaplastic thyroid carcinoma, MTC medullary thyroid carcinoma, NM not mentioned, MWA microwave ablation, ETS endoscopic thyroid surgery, RAET robotic-assisted endoscopic thyroidectomy

including upper eyelid ptosis, miosis, and ipsilateral facial anhidrosis, are typical and can occur simultaneously or independently. In addition, the facial symptoms depend on the location of the lesion, and the severity depends on the degree of impairment. First, the superior tarsal muscle is responsible for keeping the upper eyelid in a raised position after the levator palpebrae superioris muscle raises it. Thus, upper eyelid ptosis can be accompanied by impairment of the superior tarsal muscle [2]. Second, miosis, another frequent symptom in HS, indicates a disruption in the sympathetic nervous system, which dilates the pupil. In contrast, the activation of the parasympathetic nervous system plays an independent role in making the pupil smaller. Consequently, the pupil in the affected eye is relatively smaller than that in the opposite eye due to the above reasons. Notably, the degree of anisocoria (unequal pupil size) is larger in darkness than in bright light because bright light normally causes both pupils to contract [2, 32]. Last, ipsilateral facial anhidrosis, another classic presentation, is not as frequent as the above signs. However, this symptom can be more apparent after strenuous exercise or a fever [2].

According to the present case, as well as other case reports, HS usually begins within a short time (from a few hours to 3 days) after surgery $[6,17,21,26,28]$. Myosis and ptosis are the most common self-reported symptoms and can be helpful for the early recognition and diagnosis of HS in postoperative management. Nonetheless, as HS is a nonlife-threatening complication, most of the symptoms are gradually relieved within a few months. However, it is also important to note that a minority of cases showed no improvement over a long-term followup period [17, 21].

\section{Diagnosis and differential diagnosis}

First and foremost, the medical history of patients suspected of having HS needs to be evaluated carefully, as this step is regarded as the pivotal step in confirming a 


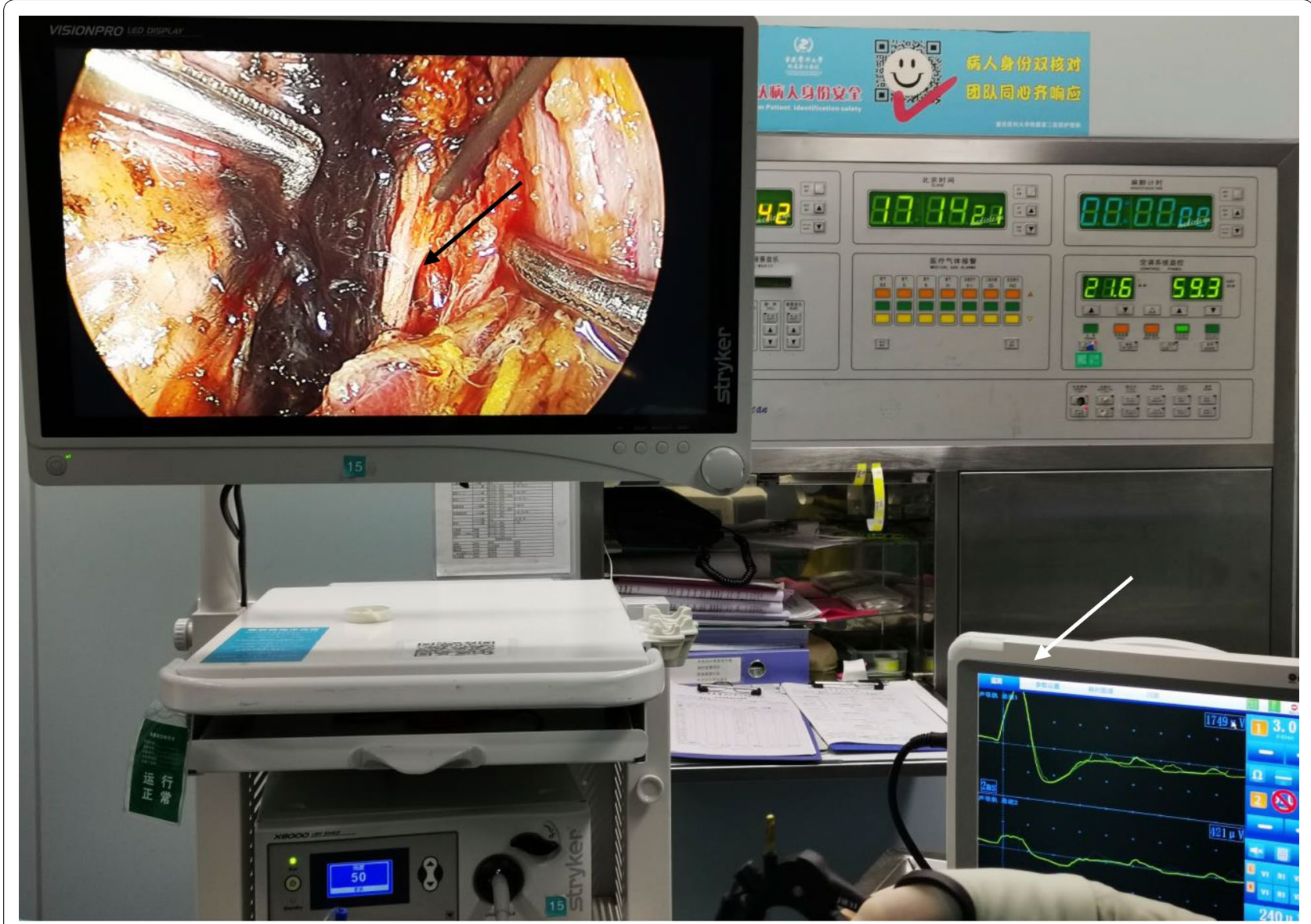

Fig. 5 The intraoperative nerve monitoring equipment. The recurrent laryngeal nerve (black arrow) and voltage fluctuation after electrical stimulation (white arrow)

definite etiology, such as trauma, neck, or chest surgery. Moreover, except for significant clinical manifestations, several key pharmacologic tests can be significantly helpful to confirm HS, especially when the diagnosis is uncertain $[33,34]$. Apraclonidine and cocaine eye drops are frequently used to confirm HS. Apraclonidine has an $\alpha-2$ adrenergic agonist with weak $\alpha-1$ activity. It has a negligible effect on pupil size. In contrast, in patients with HS, it significantly dilates the pupil because of the super- sensitivity of the iris dilator muscle from the upregulation of $\alpha-1$ postsynaptic receptors. Compared with apraclonidine, cocaine can block the uptake of norepinephrine by the presynaptic membrane and further increase the amount of norepinephrine in the synaptic cleft, dilating the pupil and raising the eyelid. Therefore, the cocaine test relies on comparing the dilation response to cocaine eye drops in an affected eye versus the normal eye. A patient can be considered positive for HS if the affected eye does not dilate as well as the normal eye. In contrast, some causes may also be involved in miosis, including but not limited to third nerve palsy and optic neuritis.
In addition, for ptosis, aging-related mechanical drooping in the eyelid is a frequent sign that needs to be distinguished from HS in elderly people.

\section{Prevention and management}

It is believed that perioperative management is crucially important for decreasing the risk of postoperative complications. Preoperatively, the surgeon needs to evaluate the nature, size, and location of lesions by conducting a comprehensive physical examination and imaging exams and then choose the appropriate type of operation. For instance, compared with ETS, conventional thyroid surgery can significantly improve the visualization of the surgical field and decrease the operation difficulty in patients with multiple central or lateral lymph node metastases. Intraoperatively, although ETS provides three-dimensional vision and a magnified view of the operative field, the difficulty of avoiding thermal accumulation is increased due to less tactile and strength feedback being provided for surgeons, 
which may result in thermal damage to surrounding tissues. As one network meta-analysis confirmed, the ultrasonic coagulation results are superior to other conventional techniques, except in decreasing the incidence of nerve injury [35]. For this reason, attention should be paid to maintaining a safe distance to the prevertebral fascia when using an ultrasonic knife to remove the thyroid lobe or performing lateral lymph node dissection. The target tissue or blood vessels should be carefully blunt separated from surrounding tissues so that we can safely perform thermal detaching. Notably, intraoperative nerve monitoring equipment (Fig. 5), one of the new types of equipment that was developed in recent years, can effectively help surgeons determine the location and degree of preservation of cervical nerves, such as the recurrent laryngeal nerve, superior laryngeal nerve, and cervical sympathetic nerve, during ETS. Postoperatively, HS is usually transient and insidious and does not result in the loss of visual function but shows cosmetic defects. Therefore, any self-reported complaints in patients, especially those associated with facial appearance, should be considered, as they can help in the diagnosis of HS in an early stage. Short-term neurotrophic therapy, such as vitamin B1 and vitamin B12 (mecobalamin), may help relieve these symptoms.

Generally, although HS is a rare complication due to thyroid surgery, especially ETS, surgeons must gain an understanding of the anatomic relationships of the cervical sympathetic and thyroid glands. In addition, standardized and appropriate operative procedures and subtle manipulation are essential in preventing and reducing the occurrence of HS. As shown in our case report, HS is not a life-threatening complication, and the majority of these cases gradually resolve within a few years. However, during this period, patients suffer from the symptoms of ptosis and miosis, which will have a negative impact on their appearance and mental health. Thus, the early diagnosis and management of this rare complication are also important for a favorable outcome.

\footnotetext{
Abbreviations

HS: Horner syndrome; HT: Hashimoto's thyroiditis; TI-RADS: Thyroid Imaging Reporting and Data System; FNA: Fine-needle aspiration;TPOAb: Thyroid peroxidase antibody; TgAb: Thyroid globulin antibody; FSB: Frozen section biopsy; TT: Total thyroidectomy; ST: Subtotal thyroidectomy; ET: Ectopic thyroidectomy; CLND: Central lymph node dissection; LLND: Lateral lymph node dissection; BCLND: Bilateral central lymph node dissection; BLLND: Bilateral lateral lymph node dissection; FTC: Follicular thyroid carcinoma; ATC: Anaplastic thyroid carcinoma; MTC: Medullary thyroid carcinoma; PTC: Papillary thyroid carcinoma; PTMC: Papillary thyroid microcarcinoma; MWA: Microwave ablation; ETS: Endoscopic thyroid surgery; RAET: Robotic-assisted endoscopic thyroidectomy; NM: Not mentioned.
}

\section{Acknowledgements} Not applicable.

\section{Authors' contributions}

$\mathrm{HC}$ analyzed and interpreted the patient data regarding the thyroidectomy by ETS. YM was a major contributor in writing the manuscript. XW edited the manuscript. YH contributed to the pathological diagnosis of this patient. GBY made substantial contributions to the conception and design of this case report. All authors read and approved the final manuscript.

\section{Funding \\ None.}

\section{Availability of data and materials}

The datasets used and/or analyzed during the current study are available from the corresponding author on reasonable request.

\section{Ethics approval and consent to participate}

Written informed consent was obtained from the patient to participate to this case report.

\section{Consent for publication}

Informed written consent was obtained from the patient for the publication of the clinical details and clinical images.

\section{Competing interests}

The authors declare that they have no competing interests.

\section{Author details}

${ }^{1}$ Department of Breast and Thyroid Surgery, The Second Affiliated Hospital of Chongqing Medical University, No.74, Linjiang Rd, Yuzhong Dist, Chongqing 404100, People's Republic of China. ${ }^{2}$ Department of Pathology, The Second Affiliated Hospital of Chongqing Medical University, No.74, Linjiang Rd, Yuzhong Dist, Chongqing 404100, People's Republic of China.

Received: 1 September 2020 Accepted: 28 December 2020

Published online: 13 January 2021

\section{References}

1. Horner F. Über eine Form von Ptosis. Klin Monbl Augenheilkd. 1869;7:193-8.

2. Martin TJ. Horner syndrome: a clinical review. ACS Chem Neurosci. 2018:9:177-86.

3. Kaelin W. Über Störungen von seiten des Halssympathicus bei einfacher Struma und im Anschluß an deren operative Behandlung. Deutsche Zeitschrift für Chirurgie. 1915;134:395-423.

4. Lee YS, Nam KH, Chung WY, Chang HS, Park CS. Postoperative complications of thyroid cancer in a single center experience. J Korean Med Sci. 2010;25:541-5.

5. Miccoli P, Berti P, Conte M, Bendinelli C, Marcocci C. Minimally invasive surgery for thyroid small nodules: preliminary report. J Endocrinol Invest. 1999;22:849-51.

6. Meng K, Tian W, Lv Z, Song X. Horner's syndrome subsequent to minimally invasive video-assisted thyroidectomy in two patients. Oncol Lett. 2015;10:459-62.

7. Tan C, Sidhu S, Sywak M, Delbridge L. Management of hyperfunctioning single thyroid nodules in the era of minimally invasive thyroid surgery. ANZ J Surg. 2009;79:386-9.

8. Han J, Park SY, Lee JY. Nationwide population-based incidence and etiologies of pediatric and adult Horner syndrome. J Neurol. 2020. https://doi. org/10.1007/s00415-020-10270-2.

9. Smith SJ, Diehl N, Leavitt JA, Mohney BG. Incidence of pediatric Horner syndrome and the risk of neuroblastoma: a population-based study. Arch Ophthalmol. 2010;128:324-9.

10. Knyazer B, Smolar J, Lazar I, Rosenberg E, Tsumi E, Lifshitz T, et al. latrogenic Horner syndrome: etiology, diagnosis and outcomes. Isr Med Assoc J. 2017;19:34-8.

11. Sabbagh MA, De Lott LB, Trobe JD. Causes of Horner syndrome: a study of 318 patients. J Neuroophthalmol. 2020;40:362-9. 
12. Jeffery AR, Ellis FJ, Repka MX, Buncic JR. Pediatric Horner syndrome. J Aapos. 1998;2:159-67.

13. Donaldson JF, Rodriguez-Gomez IA, Parameswaran R. Rapidly enlarging neck masses of the thyroid with Horner's syndrome: a concise clinical review. Surgeon. 2015;13:110-5.

14. Kang SW, Lee SC, Lee SH, Lee KY, Jeong JJ, Lee YS, et al. Robotic thyroid surgery using a gasless, transaxillary approach and the da Vinci $S$ system: the operative outcomes of 338 consecutive patients. Surgery. 2009;146:1048-55.

15. Kim J, Gosnell JE, Roman SA. Geographic influences in the global rise of thyroid cancer. Nat Rev Endocrinol. 2020;16:17-29.

16. Wang J, Yu F, Shang Y, Ping Z, Liu L. Thyroid cancer: incidence and mortality trends in China, 2005-2015. Endocrine. 2020;68:163-73.

17. Zhang $X, G e Y$, Ren P, Liu J, Chen G. Horner syndrome as a complication after thyroid microwave ablation: case report and brief literature review. Medicine (Baltimore). 2018;97:e11884.

18. Demiral M, Binay C, Simsek E, Ilhan H. Horner Syndrome secondary to thyroid surgery. Case Rep Endocrinol. 2017;2017:1689039.

19. McCrory D, Kelly A, Korda M. Postoperative Horner's syndrome following excision of incidental cervical ganglioneuroma during hemithyroidectomy and parathyroid gland exploration. BMJ Case Rep. 2020;13:e231514s.

20. Punda A, Nika Č, Bedeković V, Košec A. Delayed Horner syndrome and accessory nerve weakness after papillary thyroid carcinoma surgery. Ear Nose Throat J. 2020. https://doi.org/10.1177/0145561320907714.

21. Aslankurt M, Aslan L, Colak M, Aksoy A. Horner's syndrome following a subtotal thyroidectomy for a benign nodular goitre. BMJ Case Rep. 2013. https://doi.org/10.1136/bcr-2013-009907.

22. Perréard $M$, Bailleul $H$, Babin E. Post-thyroidectomy Horner's syndrome. Eur Ann Otorhinolaryngol Head Neck Dis. 2019;136:419-20.

23. Cozzaglio L, Coladonato M, Doci R, Travaglini P, Vizzotto L, Osio M, et al. Horner's syndrome as a complication of thyroidectomy: report of a case. Surg Today. 2008;38:1114-6.

24. Italiano D, Cammaroto S, Cedro C, Bramanti P, Ferlazzo E. Horner syndrome following thyroidectomy. Neurol Sci. 2011;32:531.

25. Seneviratne SA, Kumara DS, Drahaman AM. Horner's syndrome: an unusual complication of thyroidectomy: a case report. J Med Case Rep. 2016;10:300.
26. Sandoval MA, Cabungcal AC. Horner syndrome after radical neck surgery for anaplastic thyroid carcinoma. BMJ Case Rep. 2015. https://doi. org/10.1136/bcr-2015-209324.

27. Foma W, Pegbessou E, Amana B, Kpemissi E. Left parapharyngeal ectopic goitre associated with eutopic thyroid and postoperative Horner's syndrome. Eur Ann Otorhinolaryngol Head Neck Dis. 2017;134:207-8.

28. Sapalidis K, Florou M, Tsopouridou K, Cheva A, Niki M, Pavlidis E, et al. Horner's syndrome: an uncommon complication of thyroidectomy and selective lateral neck dissection. Curr Health Sci J. 2019;45:111-5.

29. Mastronikolis NS, Spiliopoulou SP, Zolota V, Papadas TA. Horner's syndrome incidental to medullary thyroid carcinoma excision: case report and brief literature review. Case Rep Otolaryngol. 2016;2016:7348175.

30. Hu X, Zhang X, Gan H, Yu D, Sun W, Shi Z. Horner syndrome as a postoperative complication after minimally invasive video-assisted thyroidectomy: a case report. Medicine (Baltimore). 2017;96:e8888.

31. Lee J, Yun JH, Nam KH, Choi UJ, Chung WY, Soh EY. Perioperative clinical outcomes after robotic thyroidectomy for thyroid carcinoma: a multicenter study. Surg Endosc. 2011;25:906-12.

32. Wilhelm H, Ochsner H, Kopycziok E, Trauzettel-Klosinski S, Schiefer U, Zrenner E. Horner's syndrome: a retrospective analysis of 90 cases and recommendations for clinical handling. Ger J Ophthalmol. 1992;1:96-102.

33. Koc F, Kavuncu S, Kansu T, Acaroglu G, Firat E. The sensitivity and specificity of $0.5 \%$ apraclonidine in the diagnosis of oculosympathetic paresis. $\mathrm{Br}$ J Ophthalmol. 2005;89:1442-4.

34. Mughal M, Longmuir R. Current pharmacologic testing for Horner syndrome. Curr Neurol Neurosci Rep. 2009;9:384-9.

35. Garas G, Okabayashi K, Ashrafian H, Shetty K, Palazzo F, Tolley N, et al. Which hemostatic device in thyroid surgery? A network meta-analysis of surgical technologies. Thyroid. 2013;23:1138-50.

\section{Publisher's Note}

Springer Nature remains neutral with regard to jurisdictional claims in published maps and institutional affiliations.

Ready to submit your research? Choose BMC and benefit from:

- fast, convenient online submission

- thorough peer review by experienced researchers in your field

- rapid publication on acceptance

- support for research data, including large and complex data types

- gold Open Access which fosters wider collaboration and increased citations

- maximum visibility for your research: over $100 \mathrm{M}$ website views per year

At BMC, research is always in progress.

Learn more biomedcentral.com/submissions 